\title{
Correction to: Evaluation of the combined deterioration by freeze-thaw and carbonation of mortar incorporating BFS, limestone powder and calcium sulfate
}

\author{
Wenyan Zhang $\cdot$ Seunghyun Na $\cdot$ Junho Kim $\cdot$ Hyeonggil Choi $\cdot$ \\ Yukio Hama
}

Published online: 8 November 2017

(C) RILEM 2017

Correction to: Materials and Structures (2017)

50:171

https://doi.org/10.1617/s11527-017-1039-1

Due to an unfortunate turn of events, this article was published with an erroneous version of Fig. 9. Please find on this page the correct version of Fig. 9 that should be regarded by the reader as the final version.

The online version of the original article can be found under https:// doi.org/10.1617/s11527-017-1039-1.

W. Zhang

School of Material Science and Engineering, Henan

Polytechnic University, Jiaozuo 454000, China

\section{W. Zhang}

Center of Environmental Science and Disaster Mitigation for Advanced Research, Muroran Institute of Technology, 27-1 Mizumoto, Muroran 050-8585, Japan

S. $\mathrm{Na}$

Product Development Department, Nippon Steel and Sumikin Cement Co. Ltd., 64, Nakamachi, Muroran 050-8510, Japan

J. Kim · H. Choi · Y. Hama ( $\bowtie)$

Graduate School of Engineering, College of

Environmental Technology, Muroran Institute of

Technology, 27-1 Mizumoto, Muroran 050-8585, Japan

e-mail: hama@mmm.muroran-it.ac.jp 


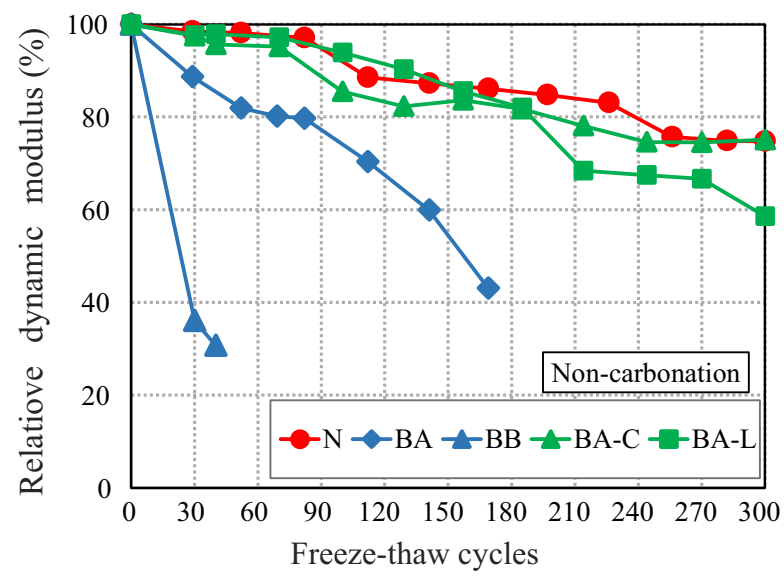

(a)

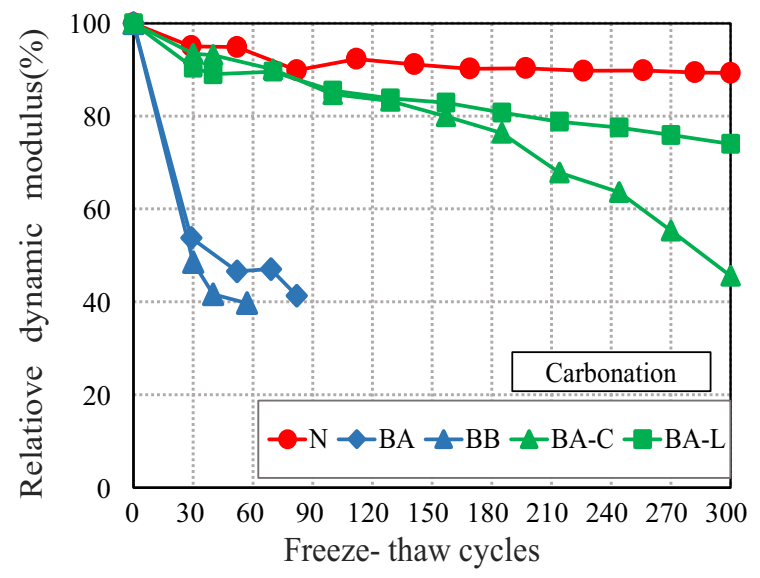

(b)

Fig. 9 Relative dynamic modulus of mortar samples without carbonation and after pre-carbonation. a Non-carbonation mortar samples. b Mortar samples after pre-carbonation 